\title{
Espaço, Comunicação e Consumo no Metrô do Rio de Janeiro ${ }^{1}$
}

\author{
Janice Caiafa $^{2}$
}

\begin{abstract}
Resumo: Neste trabalho apontamos alguns componentes do espaço construído do metrô do Rio de Janeiro e exploramos algumas de suas características, mostrando o tipo de ocupação $e$ as modalidades de comunicação que se produzem. Em seguida, nos detemos num desses componentes, os anúncios publicitários. Mostramos que há, nesse caso, um tratamento do espaço que privilegia o consumo em detrimento do direito de uso e procuramos elucidar as repercussões na sociabilidade que se desenvolve no metrô.
\end{abstract}

Palavras-Chave: Espaço Urbano, Publicidade, Metrô (Rio de Janeiro).

Abstract: In this text we individualize a few components of the built space of the Rio de Janeiro subway and explore their characteristics, showing how a specfic kind of occupation of the space and certain modalities of communication are produced in this context. We focus on one of these components - the pieces of advertisement found along the stations and on the trains - and we argue that in this case we have a treatment of the space that is centered on consumption as opposed to the right of use. We thus try to elucidate the ressonances of this situation in the sociability that develops in the subway rides.

Key-words: Urban Space, Advertisement, Subway (Rio de Janeiro).

\section{Espaço metropolitano}

Um vetor importante nas cidades e que as caracteriza fortemente é a acolhida material que produzem com suas ruas, seus edifícios, equipamentos coletivos, acessos. O espaço construído das cidades determina em parte o tipo de ocupação que vai se dar em cada caso. Em Jornadas Urbanas (CAIAFA, 2002) assinalei que a percepção do espaço urbano é densa e complexa na medida em que todos os sentidos parecem mobilizados. Entramos nesse espaço, pisamos, sentimos de alguma forma esse lugar que habitamos e a presença de nosso corpo ali. Há uma força experiencial nessa ocupação que pode evocar outras experiências e criar e modificar afetos. Os processos materiais

\footnotetext{
${ }^{1}$ Uma primeira versão deste texto foi apresentada no Grupo de Trabalho "Comunicação e Sociabilidade", do XVIII Encontro da Compós, na PUC-MG, Belo Horizonte, MG, junho de 2009.

${ }^{2}$ Janice Caiafa é doutora em Antropologia pela Universidade de Cornell, E.U.A. e Professora Associada da Escola de Comunicação da Universidade Federal do Rio de Janeiro. E-mail: scintilla1@terra.com.br
} 
se constituem em alguma medida em componentes subjetivos e desenvolvem um tipo de comunicação.

Guattari (1992) escreve que o espaço tem uma força de interpelação. Ao ocupar o espaço das cidades experimentamos de alguma forma sua força enunciativa. Ele insiste que não há que opor as coisas e a sua representação e que os fluxos materiais são também e diretamente fluxos semióticos (GUATTARI, 1994). Podemos dizer portanto que na relação com o espaço construído das cidades se desenvolve uma dimensão comunicativa (CAIAFA 2002, 2008b).

Viajar de metrô envolve penetrar num espaço singular desde a entrada de uma estação, onde encontramos as bilheterias (nesse lugar intermediário que se denomina mezanino) até as plataformas de acesso às composições. Para viajar efetuamos esse trajeto, percorrendo todo o ambiente metropolitano. Nesse deslocamento seguimos sinalizações visuais e sonoras, subimos e descemos (muitas vezes em escadas automáticas), passamos por torniquetes. Há toda uma série de ações que o meio nos demanda - inclusive no espaço itinerante das composições em que o passageiro embarca para viajar e que prolonga o das plataformas. Como já venho mostrando em vários trabalhos, trata-se de um meio exigente, marcado por regulações - que estipulam onde devemos nos posicionar, por exemplo, por onde podemos ou não prosseguir. Nesse meio há a forte presença de um componente tecnológico. Ao analisar esse aspecto da relação com a máquina nos metrôs em geral e particularmente no metrô do Rio de Janeiro, cunhei a expressão ambiente maquínico (CAIAFA, 2008b).

No metrô do Rio de Janeiro podemos observar variações estéticas no espaço construído nas diversas estações. Muito haverá a falar sobre os usos dos materiais, como o cimento e os ladrilhos, e sobre a relação desses espaços com seu entorno, no caso das estações superficiais e elevadas - o que farei num outro momento. Mas algo parece, de uma forma geral, caracterizar o espaço construído do metrô do Rio de Janeiro, aparentemente em todo o sistema. Trata-se de um espaço limpo, onde raramente se surpreende um papel jogado no chão. Essa questão é mencionada por muitos usuários e se oferece de pronto à observação do pesquisador.

Ao contrário do que se passa na maioria dos outros lugares da cidade, as pessoas preservam o espaço de lixo, utilizando as cestas nas plataformas e mezaninos. Este aspecto não pode deixar de ser mencionado porque é muito característico do espaço do 
metrô e o contraste com todo o resto da cidade é notável. Essa característica, pareceme, persiste desde os inícios do metrô na cidade.

Para a produção desse espaço clean, quase asséptico, contribuem fatores humanos e não-humanos. Há os materiais utilizados na construção, a presença da máquina, por exemplo, além das atitudes dos usuários que encontram um lugar com essas características e continuam a produzi-lo assim. Observamos que entre o sujeito e o ambiente há, de fato, uma relação de co-implicação, como coloca Varela (1995). Não temos um sujeito pronto e um ambiente dado que, num segundo momento, vão se relacionar. Mudamos e nos tornamos outra e outra coisa ao participarmos desse ambiente que também se produz com a nossa ação.

Ao construir a noção de ambiente maquínico (CAIAFA, 2008b) e para caracterizar o espaço do metrô do Rio de Janeiro, evoquei o texto de Foucault (2001) quando esse autor define "heterotopia". As heterotopias contestam os espaços de uma sociedade, constituem "outros espaços", que contrastam com os posicionamentos (emplacements) ordinários que a constituem. O metrô me parece funcionar como uma "heterotopia de compensação" que Foucault define como um dos tipos possíveis de heterotopia. Nesse caso, um espaço ordenado e perfeito é criado para compensar o caos dos espaços em torno. Um exemplo seriam as colônias fundadas no século XVII na costa leste dos Estados Unidos. O espaço do metrô do Rio de Janeiro me parece atualizar essa característica, em alguma medida, em seu contraste com a própria cidade.

Outras questões a apontar sobre os componentes desse espaço, além dos contrastes entre lugares do próprio sistema e entre estes e a cidade são, por exemplo, aspectos ligados aos avisos visuais e sonoros que procuram orientar/controlar o posicionamento durante as viagens (CAIAFA, 2007b), aos suportes de comunicação empresarial (CAIAFA. 2008c) e às sinalizações para orientação nas plataformas e mezaninos. Os usuários têm bastante a dizer sobre esses aspectos, como mostram os dados etnográficos até agora. Tenho apresentado parte desses dados e analisado alguns desses componentes.

A partir destas observações mais gerais sobre o espaço metropolitano, e apostando que conseguiram em alguma medida introduzir o leitor ao problema, vou me concentrar num outro componente desse espaço. Trata-se dos anúncios publicitários que se espalham por todo o sistema, desde o mezanino, passando pelas plataformas, até o 
espaço itinerante das composições. Com a concessão da operação do metrô ao setor privado, observou-se um particular investimento nessa modalidade de comunicação no espaço do metrô. É, portanto, em parte em conexão com esse fenômeno que procuro analisar o problema da publicidade no metrô — sua participação na produção do espaço metropolitano e suas repercussões na sociabilidade das viagens.

\section{Uso e consumo nos equipamentos coletivos}

Nossa época é marcada pela constante conversão de atividades, instrumentos e práticas de diversas ordens para os circuitos do lucro privado. O capitalismo que triunfou pela figura do Estado passa, depois da Segunda Guerra Mundial, a realizar-se preferentemente com a empresa e suas estratégias mais flexíveis e abrangentes (DELEUZE, 1990). É certo que o Estado recua apenas em sua dimensão de promotor de serviços e se torna particularmente ativo na tarefa de proteger os interesses do capital. A recente crise que atingiu o mercado de capitais e vem produzindo uma derrocada generalizada dos marcos do capitalismo requereu uma presença mais expressiva do Estado mobilizando-o justamente nessa sua função de pavimentar os caminhos do capital.

A predominância da empresa data do pós-guerra, mas foi sobretudo a partir dos anos 1980 que as diversas formas de privatização se impuseram, oficializando-se através de títulos legais e de práticas concretas. Mais e mais se descobrem recantos onde a lógica do capital poderia vigorar com proveito. Vão se multiplicando as superfícies de inscrição do capital. Uma superfície surpreendente, a meu ver, é o corpo do atleta. Já nos acostumamos a assistir atletas em campo ou dando entrevistas vestidos com os mais diversos selos empresariais, e não só de marcas ligadas ao esporte. Tanto que essas etiquetas ficam transparentes para nós, mas apenas porque somos levados a partilhar a situação contemporânea de proliferação dos emblemas do marketing. Se nos forçamos a pensar um pouco, num exercício deliberado de estranhamento, podemos subitamente ver ao menos algum grau de inadequação ou de fricção naquela vizinhança.

Essa inscrição que incita ao consumo pode atingir também o espaço construído, por exemplo, os espaços de uma cidade. Podemos pensar nos anúncios que - tão frequentemente e muitas vezes em grande número - compõem hoje a paisagem visual das cidades. Pode-se até reivindicar uma dimensão estética nesse caso — e, aliás, em 
outros casos-, mas é interessante observar que há um tratamento do espaço que a inscrição para o consumo estipula e que a caracteriza.

As marcas do marketing podem também atingir os equipamentos coletivos urbanos, imprimindo-se no seu espaço. Essa situação é frequentemente característica dos fenômenos de privatização — em que a propriedade ou a gestão desses equipamentos é entregue por concessão, permissão ou outro expediente ao setor privado —, embora ocorra também em outros contextos.

Num equipamento coletivo se presta um serviço a uma coletividade. A noção de serviço não é uniforme, daí a diversidade dos equipamentos coletivos. A rigor, contudo, a noção de equipamento coletivo se aplica principalmente ao conjunto de dispositivos espaciais que proporcionam um serviço público, ou seja, um serviço em alguma medida vital para a coletividade.

Aqui também vemos que há variação na definição de serviço público se observamos as legislações dos diversos países (PEREZ, 2006). A legislação brasileira distingue o serviço público estrito senso, como o que se presta num hospital, do serviço do transporte, chamado "de utilidade pública", caracterizado não pela "essencialidade", mas pela "conveniência", e ligado à ideia de "facilitação da vida do indivíduo na coletividade (MEIRELLES, 1995, p. 298). Nos dois casos, a Constituição Federal deixa claro que cabe ao poder público o fornecimento desses serviços e o obriga, assim como aos eventuais delegados, a "fornecer serviços adequados, eficientes, seguros e contínuos" (MEIRELLES, 1995, p. 289).

Tenho utilizado amplamente a noção de equipamento coletivo em minha pesquisa sobre o metrô do Rio de Janeiro. Em "Consumo e transporte coletivo" e "Uso e consumo no metrô do Rio de Janeiro", mostrei como, na situação de gestão privada, o direito de uso era substituído pelo fenômeno do consumo. Os passageiros não são tratados como usuários daquele serviço, como tendo direito de uso do serviço fornecido pelo equipamento coletivo, mas como consumidores, como compradores de deslocamento. É o que chamei de passagem de usuário a cliente. Mostrei como havia um tratamento característico do universo do consumo em contraste com o do uso, concentrando-me no desenvolvimento da propaganda institucional no espaço do metrô do Rio de Janeiro (CAIAFA, 2008c). O metrô do Rio de Janeiro foi inaugurado para 
operação comercial em 1979 e concedido para operação privada em 1998, tendo havido uma renovação antecipada do contrato de concessão por mais 20 anos agora em 2008.

No caso dos equipamentos de serviço de transporte há variações no que diz respeito a essa tendência de privatização. Ao contrário do que se poderia talvez imaginar, por exemplo, nos Estados Unidos o transporte urbano regional tende a ser gerido pelo setor público. Em Nova York, a MTA (Metropolitan Transportation Authority) — agência pública que gere o transporte coletivo na cidade - encampou recentemente as poucas as linhas de ônibus que eram exploradas por empresas privadas (CAIAFA, 2007a).

No Brasil se percebe que a figura da privatização no transporte se tornou mais atraente, implicando inclusive a entrada recente da ideia de marketing no setor. Pensemos na privatização dos trens urbanos e interurbanos e mesmo na concessão do metrô carioca. O maior metrô do país — o de São Paulo —, contudo, é gerido pelo setor público. Mas pode-se dizer em geral que predomina entre nós a ideia de que os serviços públicos poderiam ser explorados com sucesso por empresas privadas, acompanhando a tendência mais ampla das privatizações a partir da década de 1980 no contexto das relações globalizadas. Com exceções e variações, o transporte urbano é um setor também cobiçado pelo poder empresarial.

O regime de propriedade e o regime de gestão são cruciais num equipamento de serviço. A forma de operação de um metrô não é sem consequências para o cotidiano desse transporte e contribui para produzir as relações nas viagens. A passagem do uso ao consumo no metrô do Rio de Janeiro gera modalidades de comunicação no espaço do metrô que produzem formas de sociabilidade. O tratamento do passageiro não mais como usuário, mas como cliente, muda o funcionamento do equipamento coletivo.

É interessante observar como o espaço construído do metrô recebe novas inscrições. Ele parece se tornar uma superfície para os emblemas do marketing e do consumo, sob a lógica do negócio. É preciso notar que há fruição no mesmo golpe, como assinalam a observação participante e as entrevistas realizadas, ao mesmo tempo em que novas imposições se estabelecem.

\section{Publicidade no metrô}


Não é difícil constatar que o espaço construído do metrô do Rio de Janeiro é amplamente ocupado por anúncios. Ao menos desde o início da pesquisa, em 2005, tem sido possível observar um grande aproveitamento de basicamente todo o espaço. Desde os painéis de mezaninos e plataformas até os anúncios nas próprias composições, além dos lugares mais surpreendentes, cuja ocupação constitui um aspecto muito característico do tratamento do espaço do metrô nesse caso.

Recentemente, lembro-me de painéis de anúncios de Coristina D ao longo das estações da Linha 1 - remédio antigo que para mim tem uma propriedade de evocação. Aliás, vários usuários em entrevistas apontaram também preferências ou aspectos que lhes chamavam atenção. De toda forma, esse anúncio estava muito presente. Como anotei no caderno de campo, vi grandes painéis na estação Carioca e também ao lado de placas indicativas na mesma estação. Havia também ao longo da Linha 2 - e com certeza na plataforma da Estação Pavuna. ${ }^{3}$

Há campanhas que ocupam o interior do vagão inteiro ou quase. Há pouco tempo vi anúncios de cerveja - prenunciando, na época, o carnaval - que eram a maioria num vagão da Linha 1 . E, ainda, há os carros que são preparados de alto a baixo para anunciar algum produto. Um carro que anunciava o sabão Omo, por exemplo, tinha o chão adesivado de verde, como relva, enquanto os painéis mostravam o poder de branqueamento do produto, repetindo o verde do chão. É comum também a preparação do vagão feminino com produtos direcionados para as mulheres. Isto foi mais intenso quando da implantação desse vagão exclusivo em 2006, mas continua até hoje. São, por exemplo, anúncios de produtos de alisamento ou de xampu. Anotei em meu caderno esta frase que achei emblemática dessa interpelação das mulheres pelos anunciantes que contavam com a sua presença diante dos anúncios: "Você está preparada o brilho de Seda?"

\footnotetext{
${ }^{3}$ O metrô do Rio de Janeiro consiste num sistema de duas linhas: Linha 1 e Linha 2. A Linha 1, com 18 estações, percorre parte da Zona Sul e da Zona Norte, passando pelo Centro. A Linha 2 tem 15 estações, todas na Zona Norte, chegando à Estação Estácio da Linha 1, onde se faz a transferência entre as duas linhas. A Zona Sul é a região mais nobre e urbanizada da cidade e muitas vezes os usuários estabelecem contrastes entre a Linha 1 e a Linha 2 para vantagem da primeira, o que constitui um tema a explorar em futuros trabalhos. A Linha 1 se encaixa mais plenamente no conceito de metropolitano, com estações subterrâneas e uma demanda expressiva ao longo de todo o dia e não apenas nos horários de pico (ALOUCHE, 1990), diferentemente da Linha 2. Esta última característica produz um maior grau de exposição das estações e poderia em parte explicar o fato de que muitas vezes se observa uma presença maior de anúncios publicitários ao longo da Linha 1.
} 
Pode-se apontar ainda como muito comuns os anúncios de cursos em estabelecimentos privados, que observo desde o início da pesquisa. Também frequentes são os de crédito para casa própria, os de lojas e restaurantes em torno das estações, além das grandes campanhas, como as de celulares, de cerveja ou bancos.

Outro espaço muito aproveitado são os degraus. O Unibanco, parceiro da concessionária, anuncia muito ali. É utilizada a parte vertical de cada degrau, que tem alto grau de visibilidade. A exposição é ampla e admite mais de uma perspectiva. De longe, vê-se o anúncio repetir-se à exaustão. Subindo a escada, não cessamos de ler uma e outra, e outra vez ainda o anúncio, no ritmo da nossa marcha e, inevitavelmente, na mira do nosso olhar.

O catálogo da Metrô Rio mídia, em diálogo com seus clientes anunciantes, oferece muitos diferentes formatos para anúncios. Há os painéis de vários tipos (internos, semanal, rotativos, dupla face, etc.). Os chamados formatos especiais são, entre outros, adesivos nas escadas, bocas de túnel, relógio eletrônico, adesivo lateral de escada rolante, adesivo nas roletas, etc. Mas o texto ainda enfatiza uma abertura ou "flexibilidade". Pede que os procurem "se preferirem criar novos formatos ou ações promocionais" (Metrô Rio mídia, p. 1).

A ocupação já foi mais desenfreada e misturada, sobretudo durante o ano de 2006. Era comum, por exemplo, nos painéis internos dos trens, que vários anunciantes dividissem o mesmo painel. Eram pequenas empresas que provavelmente passavam o chapéu para pagar o preço do anúncio.

As campanhas primárias continuam numerosas hoje, ao lado das campanhas de grandes marcas, mais cuidadas. Ivan, usuário que declara apreciar os anúncios inventivos, critica as realizações mais toscas:

Então não é nada contra a presença desses anúncios no metrô, o que me incomoda é que, via de regra, a qualidade gráfica, o design desses anúncios é péssimo, é de péssima qualidade, é uma péssima qualidade de impressão ou plotagem, não sei que nome se dá. Acho muito feios aqueles pôsteres, pôsteres luminosos que tem nas estações do metrô. Agora, tem também essas campanhas que são um pouco menos ortodoxas, a colocação daquele filme adesivo nos carros, e eu já vi algumas coisas curiosas nesse tipo de publicidade. Eu lembro uma da Cebion, que eles usavam aquele tubo dos efervescentes Cebion no fundo da plataforma usando o túnel do metrô, aquela saída circular do túnel do metrô como se fosse a boca do tubo de Cebion. 
Suzana, usuária das Linhas 1 e 2, critica, por sua vez, a presença maciça de um anunciante num mesmo carro - o que é uma prática de fato comum nos metrôs em geral. O que se observa é que os usuários, sem recusar os anúncios de uma vez por todas e mesmo sabendo apreciá-los (embora aqui e ali haja críticas mais radicais), mostram suas preferências e críticas pontuais.

Porque é uma coisa que te acompanha, pelo menos dentro do trem. Ah, você tá passando de ônibus, você vê um outdoor, bacana, passou. Não, por exemplo, no trem. Geralmente eles têm uma política esquisita de num vagão colocar os, sei lá, os seis espaços pra anúncio que tem, eles colocam a mesma coisa. Você meio que tá inserido naquilo, você é obrigado a ler o anúncio, e é uma coisa que te acompanha até você sair. É um stress, você não tem opção.

Há um ano e meio ou dois anos atrás, era mais forte a tendência de colar anúncio em qualquer lugar. Viam-se anúncios até na parede que separa os trilhos, perto do sinal de perigo, ou nas colunas das plataformas. Mas ainda se encontram anúncios em lugares que não parecem apropriados — que se percebe fruto de uma idéia momentânea e da decisão de tudo aproveitar. Há alguns dias vi um enorme painel balouçando dependurado na abertura de ventilação no teto da Estação Cardeal Arcoverde, ao longo das esteiras. Era um anúncio de picolé. A empresa também costuma colar adesivos nas paredes com frequência para sua própria propaganda.

A sensação é de que se pode esperar qualquer coisa quando se trata de anúncios publicitários no metrô. Claro que o inesperado pode produzir uma interferência interessante num espaço — como já aconteceu, a meu ver ${ }^{4}$ — mas, se a estética não é forte o suficiente, o que salta aos olhos é muito mais o aspecto do improviso e do mal acabamento derterminados pelos objetivos comerciais.

Por outro lado, a exploração publicitária do espaço dos metrôs é uma fonte de renda de que muito frequentemente se lança mão, e não só no contexto das gestões privadas. Por exemplo, no metrô de Nova York, gerido pelo setor público, há anúncios. O que se verifica, ao mesmo tempo, é que a MTA (Metropolitan Transportation Authority) parece ter uma grande preocupação estética. Muitos anúncios acompanham os estilos das estações. Claro que para esta característica podem contribuir disposições

\footnotetext{
${ }^{4}$ Por exemplo, a utilização de uma mídia inovadora para anunciar produtos — um "filme" ao longo do túnel no trecho entre as estações Uruguaiana e Carioca. Placas adesivadas na parede do túnel eram iluminadas na medida em que cada imagem passava pelas janelas (PESSÔA, 2005). Essa forma de anúncio foi bastante apreciada pelos usuários. Particularmente, gostei muito desse recurso e por vezes tomava o trem só para ver de novo.
} 
dos próprios anunciantes. Há também vários projetos da agência que povoam o espaço metropolitano com arte e literatura. Parece que o que é homenageado ali antes de tudo é a experiência da viagem — e, portanto, também o usuário do metrô.

Não será assim com toda gestão pública, nem está excluído que uma gestão privada possa apresentar essa qualidade. De toda forma, acredito que a atitude de colocar o uso na frente no consumo, como no caso da MTA, — mesmo que a agência também tenha aspectos comerciais — tem um papel importante nesse sucesso.

Nas conversas com os usuários do metrô do Rio de Janeiro, a publicidade é um bom assunto. Afinal, os anúncios estão por toda a parte e em grande número. Todos dizem notá-los. Em geral, não são contra, embora várias respostas sejam sucintas, ou seja, nem sempre dizem porque gostam. "Achar legal" é uma expressão frequente. Alguns mencionam como a utilizam, como aquele usuário que disse que um dia pegou o celular e discou um número anunciado. Muitos expressam preferência por alguns anúncios ou fazem críticas a outros — como já vimos em exemplos acima.

Entre os que se expressam de forma mais genérica, é comum mencionar que os anúncios distraem. Alguns gostam dessa distração e outros apenas a veem como inevitável, já que estão ali mesmo.

- Você observa os anúncios? - perguntei a um usuário.

- Sempre. Porque é uma forma de distração, né. Querendo ou não, eu passo meia hora em cada carro, tem que olhar.

Há também algumas críticas veementes, há quem não goste, embora isto não seja comum. Além disso, pode-se constatar com clareza que muitos - em diferentes estilos - percebem o exagero no aproveitamento do espaço para publicidade.

Me incomoda essa coisa de propaganda o tempo inteiro em todos os lugares - observou um usuário. Não tem um lugar em que você possa ficar parado e você não veja um comercial de alguma coisa. E a propaganda agora é dentro dos túneis. É até divertido, você acha interessante, mas eles aproveitam todos os espaços. $\mathrm{Na}$ escada! Até nas escadarias tem propaganda.

Raquel, que costuma pegar o metrô na Estação Vicente de Carvalho, não critica, mas percebe o acúmulo de anúncios:

Às vezes eu acho exagerado. Mas ao mesmo tempo que eu acho exagerado, eu acho inteligente, porque eles aproveitam tudo. Todos os espaços possíveis que você vê, eles aproveitam.

- E o que é que você acha da presença dos anúncios? perguntei a um usuário em entrevista na Linha 1. 
— Olha, se não passar muito, se não tiver excesso, aí é válido, né?

Sr. Luiz gosta em geral dos anúncios, mas é sobretudo a favor que se aproveite o espaço para colocar fotografias da cidade para as pessoas conhecerem os diversos lugares. Ele diz que, por outro lado, não gosta de anúncios demais. E observa:

Porque senão vira uma parafernália tudo, né? Por exemplo, botar um monte de anúncio dali, então, vai ficar voltado só pra aquilo. Eu não sei, é uma coisa particular, eu não gosto muito.

As pessoas podem aceitar ou gostar de anúncios publicitários em alguns lugares e não em outros. O mesmo Sr. Luiz prefere trens sem anúncio:

É, dentro do trem eu sou contra. Dá a impressão que a pessoa tá ali pra botarem na cabeça qualquer coisa, de qualquer jeito na cabeça dela, que ela tem que comprar alguma coisa. Eu acho que a pessoa tá ali dentro, voltando pra sua casa, ou indo pro seu trabalho, ela tem que ir relaxada, ela tem que ter conforto pra ir, não ficar pensando em comprar isso, nem comprar aquilo, entendeu?

Há uma modalidade de anúncio que me parece bastante loquaz quanto a esse tipo de aproveitamento exaustivo do espaço no metrô. Trata-se da adesivagem do exterior da composição e que pode tomar dois ou mais vagões. É uma forma impositiva de publicidade. Ao mesmo tempo, a meu ver, alguns anúncios ficam ali muito atraentes, sobretudo se conseguem criar textura ou aproveitar as características do suporte. Em todo caso, tem-se uma composição que prossegue conduzindo também um anúncio publicitário, além de passageiros, e estes parecem contidos no anúncio.

Quando instados a apreciar a presença desse tipo de publicidade, alguns poucos usuários dizem que acham bom. Mas a maioria dos usuários, mesmo os que aceitam ou gostam de publicidade no metrô, não gosta dos trens adesivados. É notável a incidência da palavra "feio". O tom pode ser de aprovação dos anúncios em geral, mas, logo que mencionada essa publicidade, segue-se um "ah isto não, é feio". Uma reclamação é também que o adesivo elimina a visibilidade para quem vai entrar no trem.

Ivan, que citei acima, gosta particularmente desse tipo de anúncio, que considera inventivo. Um outro usuário, que havia dito que gosta dos anúncios, que ajudam na viagem, observa sobre a adesivagem do trem:

Mas eu não gosto porque você não tem visão do que está acontecendo dentro do veículo. Se estiver acontecendo uma coisa fora do normal, quando você for entrar, é que você vai perceber 
que você não devia ter entrado. Eu não gosto. É muita privacidade para quem não tem esse direito.

Mas não é unânime. Há, mais raramente, quem ache bonito. Gabriel, em entrevista na Linha 2, comenta:

- Ah, tá, eu acho maneiro aquele ali, teve um que eu gostei uma vez.

- Qual?

- Foi da Vivo, tava engraçado, a Vivo. E do Omo, tava tudo sujo de barro, aí o Omo passando assim, limpando. Eu achei maneiro aquela propaganda ali.

A rejeição dos usuários — não unânime, mas sem dúvida predominante — a esse tipo de anúncio parece estar ligada, portanto, a mais de uma questão. Há o problema da perda de funcionalidade da superfície do trem, mencionada por vários. Observa-se também um reconhecimento do exagero na exploração da publicidade que aqui se evidenciaria. Em alguns casos trata-se, parece-me, apenas de uma questão de gosto (ou resistência, quem sabe, ao aspecto ousado desse tipo de anúncio?). O trabalho de campo abre a possibilidade de admitir todas estas variações. Em todo caso, é interessante o fato de que os usuários tenham preferências e críticas.

É possível concluir, em geral, que não há uma recusa de uma vez por todas dos anúncios e há mesmo fruição. Ao mesmo tempo há críticas e, o que considero particularmente interessante, os usuários podem ser sensíveis de várias maneiras ao investimento na exploração do espaço do metrô, seja com uma afirmação mais peremptória, seja ao dizer que se aborrecem com o excesso de anúncios publicitários em geral ou sob certos formatos.

\section{Fazer render}

Ano passado houve uma renovação das placas de sinalização em todo o sistema do metrô. O design é bonito, com um fundo preto que valoriza o texto e compõe bem com o ambiente. Uma novidade é que todas as placas possuem espaço para publicidade. Todas as indicações de direção no espaço metropolitano podem se fazer acompanhar agora da recomendação de um produto.

No contexto da gestão privada, o usuário passa a cliente. É todo um novo tratamento que se desenvolve. Em primeiro lugar, não se é visto ou tratado como alguém que exerce seu direito de uso daquele equipamento coletivo, mas como alguém 
que vai comprar deslocamento - é o que demonstra a propaganda institucional. No caso da ocupação do espaço do metrô com anúncios de outras empresas, de que tratamos aqui, aproveita-se da presença daquelas pessoas - que ali ingressaram para se transportar - para incitá-las à compra de outros produtos que não o transporte e vendese esse recurso a outros capitalistas. Elas são tratadas como consumidoras potenciais desses outros produtos - além do transporte, igualmente posto à venda. É uma outra forma de extrair lucro de sua presença. E, no caso do metrô do Rio de Janeiro, há um investimento particular nesse tipo de expediente. Como vimos, a questão parece ser ocupar abundantemente o espaço com publicidade, explorando ao máximo essa possibilidade de utilização do espaço para fazer consumir, de inscrição para o consumo.

A venda de espaço publicitário num metrô gera uma renda alternativa muito lucrativa que se acrescenta em geral com sucesso à receita produzida com a bilheteria. De certa forma, essas pessoas são também colocadas para produzir. É preciso fazer render a sua presença ali. São agenciamentos complexos que vão determinar a extensão das zonas de lucro capitalista (CAIAFA, 2002). Práticas de diversas ordens podem se inscrever no padrão do capital. Tratados como consumidores, os usuários do metrô em alguma medida constituem força de trabalho e são anexados também à lógica do capital, tanto quanto os empregados do metrô. ${ }^{5}$

O espaço metropolitano torna-se, em grande parte, suporte para emblemas do marketing, uma superfície de inscrição para o consumo. Essas inscrições incitam ao consumo não só no sentido de levarem à compra futura dos produtos anunciados, mas também ao instaurarem uma relação de consumo com o próprio espaço. Novamente, a dimensão do uso recua - trata-se muito menos do espaço de um equipamento de serviço. O espaço metropolitano tornado suporte de publicidade não parece ter como principal função nos conduzir ou orientar, propiciando a viagem. O objetivo de nos expor aos diversos produtos (inclusive o transporte) toma à dianteira e modifica a relação com o lugar, afetando as pessoas - sensíveis de diferentes maneiras, como vimos, a esse outro tipo de acolhida.

\footnotetext{
${ }^{5}$ As anexações de segmentos diversos da populacão e, em última instância, de toda a sociedade, que o capital realiza para se valorizar constituem uma operação não só econômica, mas também política. Explorei este ponto na análise do capital do transporte no contexto das viagens de ônibus em Jornadas Urbanas (2002). Essa análise muito se inspira no trabalho de Félix Guattari (1987)
} 
Paul Virilio se ocupou bastante do problema do espaço construído nas cidades em seu trabalho. Ele coloca claramente a questão da vizinhança entre a "expressão arquitetural" e os sistemas de comunicação (VIRILIO, 1993, p. 16). Sua principal preocupação é com o fato de que a transmissão instantânea desqualifica o ambiente. Observaríamos hoje "o declínio do espaço público e de numerosos equipamentos coletivos: teatros, grandes salas de espetáculo, estádios e outros lugares" (VIRILIO, 1997, p. 72). A presença de milhares de pessoas num estádio esportivo, por exemplo, é desvalorizada em prol da transmissão ao vivo. Em conexão com isso, aponta que se tornou desejável e possível que os estádios esportivos sejam televisionados totalmente vazios, ocupados somente por painéis publicitários.

É interessante pensar que, no caso do espaço metropolitano como suporte de publicidade, há também uma espécie de esvaziamento. Embora seja evidentemente importante que os passageiros estejam lá, a sua presença está servindo a fins outros que não ao de se transportar. No universo do uso, os dispositivos do equipamento coletivo se prestam antes de tudo a garantir o exercício do direito a um serviço. A ocupação do espaço pelos usuários se justifica plenamente na busca desse fim. Na acolhida do consumo, ao contrário, a presença dos usuários é como que subordinada à presença dos anúncios.

É uma situação talvez análoga àquela dos estádios ocupados exclusivamente por publicidade. Ali o usuário do equipamento coletivo desaparece materialmente, e os que são produzidos como clientes são os telespectadores. Quem frui da atividade esportiva é o cliente das cadeias de televisão. Nesse caso, com a eliminação do usuário, o verdadeiro cliente daquele equipamento coletivo, paradoxalmente, é aquele que está ausente. No metrô, a exploração exaustiva do espaço como suporte publicitário, ao tomar os presentes como consumidores e desqualificar seu direito de uso, acabam por priorizar os interesses daqueles que anunciam, que, aliás, bem se harmonizam com os interesses de quem lhes vendeu aquele espaço. Os verdadeiros clientes estão ausentes também. Com a desqualificação do direito de uso, a operação do equipamento coletivo passa a priorizar - como no caso da ênfase na transmissão ao vivo dos jogos — outros clientes, os outros capitalistas que querem vender seus produtos usando o espaço do metrô e que não estão ali, mas que acabam, em alguma medida, por tomar precedência sobre os que estão. 
O espaço sofre, portanto, uma desqualificação quando ele é tornado suporte do consumo. Em alguma medida, há um certo tipo de esvaziamento e uma desqualificação do espaço como realização do direito de uso, como conjunto de dispositivos voltados para o fornecimento do transporte. A situação em que há o aproveitamento de cada recanto do espaço metropolitano para publicidade mostra-o com mais clareza. Vê-se como o espaço também é colocado para render.

Não há que condenar de uma vez por todas a utilização do espaço de um metrô para publicidade. A questão é perceber como isso se realiza, qual o tipo de tratamento do espaço que se desenvolve em cada caso e quais são os seus resultados. Por exemplo, se a renda produzida contribuir para a modicidade da tarifa, ou se um cuidado em referir as interferências à estética do espaço e à experiência da viagem prevalecer, não haveria desqualificação do espaço ou da presença do passageiro no sentido que apontamos. Nesse caso, o uso se colocou na frente do consumo.

No metrô do Rio de Janeiro o espaço não é totalmente destituído de suas outras funções. O equipamento coletivo se presta à tarefa de conduzir, e outros laços que não os do consumo se produzem. ${ }^{6}$ Trata-se de notar o tipo de tratamento do espaço que prevalece e observar os efeitos de poder que se extraem daí, além das possibilidades de fruição.

\section{REFERÊNCIAS BIBLIOGRÁFICAS}

ALOUCHE, Peter Lwdwig. A Tecnologia dos Metrôs do Mundo. Revista dos Transportes Públicos - ANTP. Ano 12, nº 49, setembro 1990.

CAIAFA, Janice. Os homens, as mulheres e o metrô. Ecos Urbanos: a cidade e suas articulações midiáticas. Prysthon, Angela e Cunha, Paulo (orgs.). Porto Alegre: Sulina, 2008a

. Tecnologia e sociabilidade no metrô. Revista da Associação Nacional de Programas de Pós-Graduação em Comunicação/ E-Compos. Brasília. v. 11, no 1 , jan./abr. 2008b.

. Uso e consumo no metrô do Rio de Janeiro. Revista Famecos. Porto Alegre, $\mathrm{n}^{\circ}$ 35, abril de 2008c.

$2007 a$

. Aventura das Cidades: ensaios e etnografias. Rio de Janeiro: Editora FGV,

- Comunicação e sociabilidade nas viagens de metrô. Comunicação e

\footnotetext{
${ }^{6}$ Para uma análise das relações que se estabelecem durante as viagens de metrô, ver Caiafa (2006), "Solidão Povoada".
} 
sociabilidade: cenários contemporâneos. CAIAFA, Janice; ELHAJJI, Mohammed (orgs). Rio de Janeiro: Mauad, 2007b.

. Consumo e transporte coletivo. Revista ECO-PÓS, volume 9, n.2, agostodezembro de 2006. Rio de Janeiro: e-papers, 2006a.

. Solidão povoada: viagens silenciosas no metrô do Rio de Janeiro. Contemporanea, Revista de Comunicação e Cultura, vol. 4, n 2, dezembro de 2006. Disponível em: <www.contemporanea.poscom.ufba.br> Acesso em 11/06/2009. 2006b.

. Jornadas Urbanas: exclusão, trabalho e subjetividade nas viagens de ônibus na cidade do Rio de Janeiro. Rio de Janeiro: Editora FGV, 2002

DELEUZE, Gilles. Post-Scriptum sur les sociétés de contrôle. Pourparlers. Paris: Les Éditions de Minuit, 1990.

FOUCAULT, Michel. Vigiar e Punir. Petrópolis: Vozes, 1995 [1975].

. Des espaces autres. Dits et Écrits II, 1976-1988. Paris: Gallimard, 2001.

GUATTARI, Félix. Caosmose: Um novo paradigma estético. Rio de Janeiro: editora 34, 1992.

L'an 01 des machines abstraites. Chimères. Félix Guattari - Textes et Entretiens, vol 2, , nº 23, Été 1994.

Brasiliense, 1987.

Revolução Molecular: pulsações políticas do desejo. São Paulo:

MEIRELLES, Hely Lopes. Direito Administrativo Brasileiro. São Paulo: Malheiros Eidotores, 1996.

MURARD, François; FOURQUET, Lion. Genealogie du Capital. 1. Les équipements du pouvoir. Villes, territoires et équipements collectifs. Recherches. Numéro spécial, décembre 1973.

PEREZ, Marcos Augusto. O risco no contrato de concessão de serviço público. Belo Horizonte: Fórum, 2006.

PESSÔA, Thaís. Em alta velocidade: Opção inusitada de mídia explora túneis do metrô carioca. Edição 80, 2005. www.professionalpublish.com.br

VARELA, Francisco J. Sobre a Competência Ética. Lisboa: Edições 70, 1995.

VIRILIO, Paul. O Espaço Crítico. Rio de Janeiro: Ed. 34, 1993.

Metrô Rio mídia (publicação da Metrô Rio) 